\title{
Attitudes and Beliefs of Students and Lecturers about Educational Theories: Results of a Mixed Methods Study
}

\author{
Stefan T. Siegel, ${ }^{1}$ and Martin Daumiller ${ }^{2}$ \\ ${ }^{1}$ Department of Educational Science, University of Augsburg \\ ${ }^{2}$ Department of Psychology, University of Augsburg
}

THIS PAPER IS A PREPRINT.

Please do not cite or distribute any portion without authors' permission.

\section{Author note}

Stefan T. Siegel (D) https://orcid.org/0000-0002-7065-1306

Martin Daumiller (iD https://orcid.org/0000-0003-0261-6143

We have no known conflict of interest to disclose. This research did not receive any specific grant from funding agencies in the public, commercial, or not-for-profit sectors.

Correspondence concerning this article should be addressed to Stefan Siegel, Dept. of Educational Science, Universitätsstr. 10, 86159, Augsburg, Germany. E-Mail:

Stefan.Siegel@phil.uni-augsburg.de 
ATTITUDES AND BELIEFS ABOUT EDUCATIONAL THEORIES

\section{Highlights}

- We investigated educational theories, a constitutive element of teacher education.

- Specifically, we examined students' and teachers' attitudes and beliefs thereof.

- Results documented rather negative attitudes and naïve beliefs in students.

- Attitudes and beliefs were strongly tied to motivations and emotions.

- Taken together, this stresses their relevance for teaching and teacher education. 


\title{
ATTITUDES AND BELIEFS ABOUT EDUCATIONAL THEORIES
}

\begin{abstract}
Educational theories are central for teacher education. Despite their theoretical relevance, students' and lecturers' understandings of educational theories and their theory-related attitudes and beliefs thereof are hardly understood. To elucidate these constructs and to test their relevance, we conducted a mixed methods study with 32 students and 12 lecturers. We found that both groups perceived educational theories as rather abstract concepts. Students reported rather negative attitudes and naïve beliefs. For both populations, we found that attitudes and beliefs were strongly tied to motivational and affective aspects when dealing with educational theories, which stresses their relevance for teaching and teacher education.
\end{abstract}

Keywords: Educational theories, theory-related attitudes, epistemic beliefs, professional development, teacher education, mixed methods 
Attitudes and Beliefs of Students and Lecturers about Educational Theories: Results of a Mixed Methods Study

Educational theories are a constitutive element of educational studies and teacher education (Aubrey \& Riley, 2019; Matthes, 2007). Thus, both university students and lecturers can be expected to form attitudes and beliefs about them (Green \& Hood, 2013; Richardson, 1996). These theory-related attitudes and beliefs can be considered highly relevant, as aspiring educators are expected to acquire and rely on scientific evidence (e.g., educational theories) when making professional decisions (Parr \& Timperley, 2008). Furthermore, attitudes and beliefs also hold a central role in theoretical models about teacher competencies (e.g., Baumert $\&$ Kunter, 2013). Despite their relevance, prior research indicates that pre-service teachers and practitioners tend to devalue scientific educational knowledge (Gitlin, Barlow, Burbank, Kauchak \& Stevens, 1999; Merk et al., 2017). Considering the important role that students and teachers in educational studies and teacher education programs hold within the educational system, these findings are particularly concerning and suggest the need for better understanding students' and teachers' attitudes and beliefs about educational theories, especially as the latter are a part of educators' professional knowledge (Baumert \& Kunter, 2013). However, until now, little is known about how students and lecturers perceive and assess educational theories (Aubrey \& Riley, 2019) — a limitation that we seek to address in the present work.

Attitudes and beliefs can be thought and action guiding and may be systematically associated with different motivations (e.g., learning goals) and academic emotions (e.g., enjoyment), and thus influence learning and teaching processes that may foster or hinder individual professionalization (Maio et. al, 2019; Richardson, 1996). Although there is research related to other attitude and belief objects (e.g., science) and their interrelations with motivational and affective aspects of learning and instruction, attitudes and beliefs about educational theories in particular remain rather uninvestigated prerequisites of individual 
professionalization (Maio et al., 2019; Baumert et al., 2013). Analyzing students' as well as lecturers' attitudes and epistemic beliefs about educational theories and their interrelations with motivational and affective aspects of individual professionalization is thus a seldom pursued, yet highly promising research endeavor which may help to better understand professional development of students and lecturers and improve learning processes (e.g., scholarship of teaching and learning; Dewar et al., 2018).

Therefore, in the present article we present a multi-perspective mixed methods study exploring theory-related attitudes and beliefs of university students and lecturers of a German University.

\section{What are Educational Theories?}

Educational theories are a form of educators' professional knowledge, i.e. 'general pedagogical knowledge' (Shulman, 1987, p. 8). Therefore, learning and teaching such theories are important aims for students and lecturers within educational studies and teacher education (Matthes, 2007; Merk et al., 2017).

Although scientists and policy makers frequently refer to "educational theories" when discussing learning and instruction, they scarcely define this term (Carr, 2006). According to Lenzen (2004), there is not yet a consensus about what educational theories are and which of them should be essential aspect of study programs. This is surprising, as the term 'educational theories' is (or least should be) a fundamental one within educational research. To obtain a working definition for the present study, we subsequently contrast different perspectives.

Especially in the English-speaking world, educational theories seem to be an umbrella term for theories surrounding the phenomenon education, which are used in different scientific disciplines such as psychology and philosophy (Aubrey \& Riley, 2019; Irby et al., 2013). In the Anglo-American tradition, these disciplines are referred to as educational 
sciences which aim to describe and explain educational phenomena (Leś, 2017). Against this backdrop, educational theories in a broader sense can be defined as a set of statements or principles that may help to recognize, describe, understand, explain, and predict education and learning (Irby et al., 2013).

In some non-English-speaking countries (e.g., Germany, Finland), however, the academic study of educational processes and practices is assigned to a scientific discipline in its own right: educational science (often synonymously referred to as Pädagogik; Biesta, 2013). Disciplines such as psychology or philosophy are conceived as adjacent disciplines that have their own objects of interest, perspectives, and questions (Biesta, 2013). When educational science is understood as an autonomous discipline that has its own identity and genuine educational questions, educational theories in a narrow sense can be defined as a systematically ordered system of explanatory hypotheses, and assigned observations of educational reality that are based on the fundamental concepts of educational science: education, bildung, and socialization (Vogel, 2019). Educational theories aim to describe or explain, for instance, educational processes or the goals, forms, and methods of education, and to provide frameworks for educational science and pedagogical practice (Irby et al., 2013; Vogel, 2019).

As (aspiring) educators may have varying understandings, the present study is based on a broad working definition of educational theories to be able to explore the participants' perspectives. Throughout educational studies, students and lecturers are confronted with educational theories and are likely to develop a subjective understanding of what educational theories are, along with theory-related attitudes and beliefs (see Introduction). In addition to making the term 'educational theories' scientifically tangible for students and lecturers, research on their theory-related attitudes and beliefs and their interrelations with motivational and affective aspects of individual professionalization can be regarded as highly relevant in 
order to describe and explain their experience and behavior (Maio et al., 2019; Richardson, 1996). To this end, research avenues that particularly require further investigation entail what university students and lecturers of educational science and teacher education think about educational theories, how they assess them, and what motivations and emotions they have when dealing with them.

\section{Attitudes About Educational Theories}

Despite having different understandings of professional competence, most established models of teacher competencies comprise educators' attitudes besides beliefs, motivational orientations, self-regulatory skills, and professional knowledge (e.g., Baumert \& Kunter, 2013). Following Eagly and Chaiken (2007), an attitude can be characterized as 'a psychological tendency that is expressed by evaluating a particular entity with some degree of favor or disfavor' (Eagly \& Chaiken, 2007, p. 582). According to Maio et al. (2019), a negative, neutral, or positive evaluation of an attitude object — such as people, events, and also rather abstract topics such as educational theories - manifests itself in cognitive representations (e.g., deeming educational theories as useful), in affective reactions (e.g., enjoying dealing with educational theories) and in (intended) behavior (e.g., avoiding dealing with educational theories).

Different methods for measuring attitudes have been developed to this end: Attitudes are typically measured by self-reports (e.g., semantic differentials, interviews) and less frequently, also with indirect measures such as the implicit association test (Maio et al., 2019). Although qualitative interviews are time-consuming, participants are able to dwell on their attitudes and the immediate reaction of the respondents to the question can be observed by the interviewer. Interviews are often supplemented by questionnaires that allow for the further collection of personal information about the respondents (Flick, 2018; Maio et al., 2019). 
Whether and how attitudes and behaviors — related to the attitude object—are associated has been controversially discussed within psychological research (Guyer et al., 2015). Although meta-analyses of attitude-behavior studies vary in their findings, they collectively provide evidence that attitudes significantly and substantially predict future behavior (e.g., Wicker, 1969, Kraus, 1995). Attitudes about educational theories, which are a constitutive element of educational studies and teacher education, could therefore be a viable construct to describe and explain students' and lecturers' individual professionalization as well as their motivations and emotions when dealing with educational theories (Richardson, 1996; Rodríguez et al., 2012).

\section{Epistemic Beliefs About Educational Theories}

Similar to attitudes, epistemic beliefs are considered an important aspect of educators' professional competence that play an important role for learning and instruction (Baumert \& Kunter, 2013; Richardson, 1996; Hofer, 2016). Epistemic beliefs are essentially a person's beliefs about the nature of knowledge and knowing. Specifically, they can be defined as individuals' assumptions about the origin, nature, limits, and certainty of knowledge (Hofer \& Pintrich, 1997).

Numerous models are used to conceptualize epistemic beliefs (Hofer, 2016). The well-known and widely used model by Hofer and Pintrich (1997) postulates that epistemic beliefs evolve from naive to more differentiated beliefs regarding four dimensions that can also be applied to educational theories: (1) certainty of knowledge (educational theories are valid for all time vs. tentative and evolving), (2) simplicity of knowledge (educational theories are simple vs. complex), (3) source of knowledge (educational theories are provided by external authorities vs. self-constructed), and (4) justification of knowing (educational theories are justified solely by authorities vs. by evaluating scientific evidence). 
Similar to the research on attitudes, various qualitative and quantitative approaches exist that are used to measure epistemic beliefs (Shraw \& Olafson, 2015). A strength of qualitative approaches (such as problem-centered, i.e., semi-structured interviews) is that they allow participants to elaborate on their beliefs and justify them in-depth. Whereas standardized surveys are suitable to collect background information about the respondent, interviews have the advantage that both the interviewer and the interviewee have the possibility to ask clarifying questions (Witzel \& Reiter, 2012).

Although there are also controversial findings, a substantial amount of research emphasizes the importance of epistemic beliefs for learning and teaching (Green \& Hood, 2013; Merk et al., 2017). Previous studies have shown, for instance, that students' beliefs are related to their achievement goals and in turn, learning strategies and achievement (Hofer, 2001; Mason, et al., 2013; Sinatra, 2016). While attitudes bias the selective processing of information during learning, epistemic beliefs serve as a filter through which attitudinally relevant information can be interpreted and evaluated (Maio et al., 2019; Merk et al., 2017). As epistemic beliefs impact individuals' perceptions and interpretations of reality, they are thought to act as antecedents of motivations and emotions of students and lecturers when approaching professional knowledge, in particular, educational theories (Sinatra, 2016).

\section{The Present Study}

In educational studies and teacher education, dealing with educational theories is one of the crucial tasks that students and lecturers are confronted with. Theory-related attitudes and beliefs can be deemed relevant prerequisites of their individual professionalization, yet remain largely neglected in research—especially their interrelations with motivational and emotional constructs, which are hypothesized proximal predictors of engagement with certain tasks. In this study, we focused on subjective task value, learning approach and work avoidance goals, interest in educational theories, and academic emotions when dealing with 
educational theories, as they are well-researched constructs and seem particularly promising in describing and explaining why students and lecturers might deal or not deal with educational theories.

Based on the wider definition of educational theories, we conducted a field-opening mixed-methods study with the following two central research questions:

(RQ1) What attitudes do university students and lecturers have about educational theories?

(RQ2) What epistemic beliefs do university students and lecturers have about educational theories?

Through these research questions, we aimed to provide first indications regarding the relevance of attitudes and beliefs about educational theories by subsequently investigating a third research question:

(RQ3) How are university students' and lecturers' theory-related attitudes and beliefs associated with their task value, learning approach goals, work avoidance goals, interest, enjoyment, boredom, and anxiety when dealing with educational theories?

We assumed that university students and lecturers report attitudes that span from negative to positive, as well as beliefs that range from naïve to differentiated. We propose that their theory-related attitudes and beliefs can be distinguished (i.e., they represent different constructs). Additionally, we expected university students' and lecturers' perceived subjective task value of educational theories, interest in educational theories, learning approach goals, and academic emotional experiences of joy to be positively associated with their positive attitudes and differentiated beliefs about educational theories. Furthermore, we presumed that their work avoidance goals and emotional experiences of boredom and anxiety 
would be negatively associated with their theory-related attitudes and beliefs. Finally, we expected that the stated association can be found for students and lecturers.

\section{Method}

To gain a deeper understanding of university students' and lecturers' theory-related attitudes and beliefs as well as their interrelations with motivational and affective aspects of learning and instruction, we conducted an explorative, multi-perspective mixed methods study (Creswell \& Creswell, 2018). Regarding the qualitative aspect, we conducted problemcentered (i.e., semi-structured guideline-based) interviews with students and lecturers of educational studies and teacher education. They were analyzed by means of qualitative text analysis, which is considered to be a robust method for analyzing large portions of qualitative data (Kuckartz, 2014). Concerning the quantitative aspect, we used a paper-and-pencil questionnaire to economically assess motivational and affective aspects of the participants' individual professionalization.

\section{Sample}

To obtain a heterogeneous sample for the present study, we employed a purposive sampling strategy and recruited the participants systematically based on several criteria (students: e.g., semester, degree; lecturers: e.g., status, professional experience; both: e.g., gender; Flick, 2018).

The sample comprised a total of 32 students and 12 lecturers of educational studies and teacher education from a public university in the Southern Germany. They participated voluntarily and anonymously and provided informed consent. The present study was conducted in full accordance with the Code of Ethics of the American Educational Research Association (AERA, 2011). 
The student sample encompassed 32 students of educational studies and teacher education from nearly all semesters. The students' mean age was 23.9 years $(S D=3.0$; range: 18-32 years) and $56.3 \%$ of the participants were female.

The sample of the university lecturers consisted of 12 lecturers from different disciplines (e.g., educational studies, psychology, sociology) with different academic status (5 without $\mathrm{PhD}, 4$ post-docs, and 3 full professors). Their mean age was 42.6 years $(S D=9.9$; range: $32-64)$ and 50\% were female. Half of the lecturers had substantial teaching experience including 16 years or more, and only $25 \%$ had less than 5 years of teaching experience.

\section{Data Collection and Measures}

\section{Problem-Centered Interviews}

The self-developed interview guide for the problem-centered interviews with students and lecturers comprised a total of 16 open questions ${ }^{1}$ and consisted of four thematic areas: (1) dealing with educational theories (4 questions, e.g., Regarding your studies/your current position - to what extent and in which ways have you dealt with educational theories so far?), (2) relevance of educational theories (3 questions, e.g., What do you think-what are the main functions of educational theories?), (3) beliefs (6 questions, e.g., What do you thinkhow certain are educational theories?) and (4) attitudes about educational theories (3 questions, e.g., When you think about educational theories-would you consider yourself as someone who is rather in favor or disfavor of educational theories?). The interview guide was pretested within 3 trial interviews and improved several times before data collection.

The interviews were led by the first author and trained assistants. The interviews lasted an average of 33 minutes ( $S D=7.3$; Range: 22-56 minutes) for students and 78 minutes ( $S D=21.5$; Range: 43-115 minutes) for teachers. Field notes were taken for all interviews. 


\section{Quantitative Measures}

Immediately after the interview, the participants completed a paper-and-pencil questionnaire. Example items and internal consistencies (when possible, we used McDonald's $\omega$ as a more robust coefficient than Cronbach's $\alpha$; Dunn et al., 2014) are displayed in Table 2.

\section{Motivational Aspects}

For measuring students' and lecturers' task value when engaging with educational theories, we adapted a scale by Ziegler et al. (2008). With 3 items each, intrinsic value, attainment value, and instrumental value were measured on a Likert-type scale ranging from 1 (not true at all) to 6 (completely true). Justified by strong correlations between the three subscales $(r=.66-.86, p<.001)$ and in line with other research in the field (e.g., Dietrich et al., 2017), we combined the 3 facets into one variable expressing participants' general task value when dealing with educational theories.

To measure participants' learning approach and work avoidance goals, we used a scale by Author et al. (2019) that assesses each goal type with four items on a Likert-type scale ranging from 1 (I do not agree at all) to 8 (I completely agree).

Finally, we measured interest in educational theories using a single item from the SEEQ (Marsh, 1982) that was to be answered on a Likert-type scale ranging from 1 (very low) to 5 (very high).

\section{Emotions}

We measured participants' emotions when dealing with educational theories using items from the academic emotion questionnaire (AEQ) by Pekrun et al. (2011). With two items each, we assessed enjoyment, boredom, and anxiety. The items were answered on Likert-type scales ranging from 1 (not true at all) to 6 (completely true). 


\section{Data Analyses}

\section{Qualitative Content Analysis}

All interviews were recorded, transcribed verbatim, and anonymized (students: interviews 1-32; in total 339 pages; lecturers: interviews 33-44; in total 260 pages). We used MAXQDA 2020 to analyze the transcriptions by means of qualitative text analysis. For this purpose, we developed a set of categories in which the main categories were derived deductively and the subcategories inductively (Kuckartz, 2014; see supplement 1). For the main categories (examples of educational theories, attitudes, and beliefs), $10 \%$ of the interviews were randomly selected and then coded separately by two coders. Krippendorff's alpha ranged from .91 to .95 , which indicates excellent inter-coder reliability. Remaining disagreements were consensually resolved and operational rules established. The first author then used these rules to code the remaining material (Krippendorff, 2019). For the quantitative analyses, participants were categorized regarding their attitudes and beliefs about educational theories (see Table 1).

\section{Statistical Analyses}

We used bivariate correlations (Pearson's $r$ for continuous variables and Spearman's $\rho$ for ordinal variables) to test the interrelations between the respondents' theory-related attitudes and beliefs and the motivational and affective aspects of learning and instruction. Over all variables and participants, there were less than $1.0 \%$ missing data per variable, which was dealt with using the full information maximum likelihood method (FIML). All analyses were conducted in $R$ (R Core Team, 2020; Version 1.1.463).

\section{Results}

\section{Understandings, Attitudes and Beliefs Regarding Educational Theories}

The majority of the interviewees — students as well as some lecturers-expressed uncertainty about what the term educational theory means. While some admitted that they 
"don't have a specific definition in mind right now" (S21: 112) or that they "haven't given it that much thought" (L05: 156) others defined educational theories simply as "opposed to practice” (S01: 11). Furthermore, 11 out of the 44 interviewees, including 9 students and 2 lecturers, were not able to spontaneously provide an example of an educational theory. The answers of the remaining interviewees differed considerably. While some could name a genuine example of an educational theory in a narrow sense such as "Sünkel's educational theory" (L01: 17), others referred to, for instance, sociological theories such as Bourdieu's "theory of capital" (S29: 85) or psychological models, e.g., "the [Atkinson-Shiffrin] memory model" (S08: 75).

The respondent's attitudes about educational theories differed considerably. Eleven of the interviewed students expressed their rather negative attitude by referring to educational theories as "far from reality" (S14: 86), "useless" (S01: 83), "vague” (S06: 22) or "dry" (S09: 87). Interestingly, none of the lecturers expressed such an attitude. One student responded to the question of how much educational theory should be part of educational studies and teacher education at university with "zero" (S01: 21). In contrast, seven students and seven lecturers evaluated educational theories in a positive manner: "Educational theories, this is absolutely my thing. I'm greatly interested in them" (S05: 79) or "[v]ery positive, because they help me to better understand my own life, my personal development [...] and also help me to cope better with teaching at university" (L01: 63). Over a third of the interviewees, including 14 students and 4 lecturers, evaluated educational theories ambivalently. Regarding the question concerning whether the interviewees see themselves as someone who is rather in favor or disfavor of educational theories, they answered, for example, as follows: "Neither. (laughs) [...] I'm in favor of them, if I can put them into practice. However, if I have the impression, that they only have an end in themselves then I'm rather annoyed" (L09: 119). 
The interviewees held a wide range of epistemic beliefs about educational theories that extended from rather naïve to rather differentiated beliefs. Of the interviewed students, 13 expressed rather naïve beliefs on educational theories, while lecturers seemed more educated on the topic Some interviewees held the belief that they stem from "subjective opinions" (S21:35) and that some experts "simply come up" (S17: 14) with them. In contrast, 14 interviewees, comprising 7 students and 7 lecturers voiced rather sophisticated beliefs on educational theories (e.g., that they are tentative and evolving): "I think that educational theories that are well researched probably have a true and stable core, but nonetheless they're not 100\% certain" (S03: 56) or "I think [educational theories] are adaptable, they should also be adapted in the face of new political, social and cultural challenges" (L2: 53). Around a third of the interviewees, including 12 students and 5 lecturers expressed partly naïve and partly differentiated beliefs on educational theories.

In summary, the qualitative data shows that there is high heterogeneity among university students' as well as lecturers' understandings of educational theories, as well as their theory-related attitudes and beliefs. In contrast to the students, the interviewed lecturers held no negative and no naïve beliefs about educational theories. As the classification of the interviewees regarding their theory-related attitudes and beliefs shows, eight different groups could be identified (see Table 1).

\section{Associations of Attitudes and Beliefs with Motivational and Affective Aspects of Learning and Instruction when Dealing with Educational Theories}

Descriptively, participants reported rather favorable motivations and emotions regarding educational theories (e.g., moderate to high means for task value, learning approach goals, and enjoyment, low means for boredom and anxiety; see Table 2). Simultaneously, there were substantial inter-individual differences between the different respondents (reflected in the high standard deviations) that were meaningfully associated 
with their attitudes and beliefs regarding educational theories that were determined in the interviews.

Participants with positive attitudes reported stronger task-value and learning goals, less work avoidance goals, more interest, more enjoyment, and less boredom regarding educational theories than participants with negative attitudes about educational theories. These associations were quite strong and found for both students and lecturers - with the exception of work avoidance goals and boredom, which did not differ statistically significantly depending on the lecturers' attitudes (descriptively the effects were similar to the students, which indicates that this is primarily a function of the smaller sample size of the lecturers).

Depending on the participants' beliefs on educational theories, we found differences in motivations and emotions for students, but not for lecturers. Students with more differentiated beliefs reported stronger task value and learning goals, less work avoidance goals, higher interest, and more enjoyment than those with naïve beliefs. No statistically significant associations were found between students' or lecturers' beliefs and the emotions of boredom and anxiety. Also descriptively, the effects for lecturers were very small.

\section{Discussion}

In this field opening mixed methods study, we investigated students' and lecturers' attitudes and beliefs regarding educational theories and tested their relevance for motivational and emotional processes when dealing with such concepts. Given the central role of educational theories, understanding students' and lecturers' subjective understandings, their theory-related attitudes and beliefs, as well as their motivations and emotions is an important step towards more comprehensively understanding how and why students and lecturers of educational studies and teacher education deal with educational theories or rely on them in practice. Besides its focus on under investigated aspects of students' and lecturers' individual 
professionalization, a particular strength of the present work is its multi-perspective approach (considering both students and lecturers).

Although the term 'educational theories' is commonly used in educational contexts and can be considered a fundamental concept of educational science, educational theories were perceived by both groups to be very abstract and vague (Carr, 2006). A majority of the interviewed students (even the ones in higher semesters), but also some lecturers, had great difficulties in defining the term and in providing adequate examples. As expected, most of the participants, students and lecturers alike, referred to educational theories in a broader sense by naming examples of psychological or sociological theories and did not directly associate theories of education and bildung in a narrow sense with the term 'educational theories' (see defining educational theories). This might be due to the lack of a clear definition in scientific educational literature (Lenzen, 2004). To this end, if lecturers were to place an increased focus on the question of what educational theories are, this could lead to more clarity from which students could benefit. Differing in their degree of sophistication, in particular, the students' responses were often pervaded by vague and prescientific understandings (e.g., 'theory and practice are something completely different'). This might point to a potential lack of meta-knowledge about (educational) theories, for example, regarding the certainty, simplicity, and functions of scientific knowledge that could be addressed in educational studies and teacher education.

Nevertheless, students and lecturers are regularly confronted with educational theories within educational studies and teacher education. Despite particularly students frequently not having a scientifically accurate scientific understanding of the concept, they still form attitudes and beliefs about it that we consider as decisive for how they engage with educational theories. To this end, our results reinforced that attitudes and beliefs can be distinguished from each other, while both the theory-related attitudes and the beliefs of the 
respondents differed considerably. In line with theoretical evidence, we found attitudes that ranged from negative to positive and beliefs that ranged from naïve to differentiated (Hofer, 2016; Maio et al., 2019). Our findings showed that especially students evaluated educational theories more negatively and held more naïve beliefs, which is in line with prior research on pre-service teachers and practitioners (Gitlin et al., 1999; Merk et al., 2017). Lecturers might have more positive attitudes and more sophisticated beliefs about educational theories as they might be confronted more often with them and have stronger intrinsic motivation to deal with theoretical concepts than students. Nevertheless, the degree to which negative attitudes and naïve beliefs about educational theories affect students' and lecturers' individual professionalization remains unclear.

Taken together, these findings shed light on the configurations of attitudes and beliefs about educational theories and suggest that they are clearly distinct concepts that can meaningfully inform us about why individuals engage differently with educational theories. Regarding the latter point, we provided first indications of the different correlation patterns with motivational and affective aspects of individual professionalization.

That both students' and lecturers' attitudes were strongly associated with their motivations and emotions regarding educational theories stands in line with prior research (Richardson, 1996; Rodríguez et al., 2012). Concerning the participants' beliefs, the associations with motivational and affective aspects of individual professionalization tended to be much weaker for students, while no statically significant findings emerged for lecturers. Especially interesting is the association with boredom. While there was a strong negative link for students' attitudes, the beliefs were hardly associated with boredom. This could point to attitudes and beliefs underlying different affective mechanisms, with attitudes being primarily relevant for one's appraisals and beliefs being tied to more strongly cognitive valuations of the construct in question (Maio et al., 2019; Merk et al., 2017). As such, beliefs might matter 
more strongly for engagement and decisions to engage with the constructs (e.g. research, Gitlin et al., 1999). An explanation for the less favorable effects for the beliefs might be that they comprise a different dimension that should be distinguished in future research endeavors. Based on this, we conclude that both attitudes and beliefs appear meaningful for explaining students' and lecturers' engagement in educational theories (Richardson, 1996; Sinatra, 2016).

Despite the small sample, the high heterogeneity among the participants regarding their attitudes and beliefs about educational theories and strong interrelations with important aspects of learning and instruction, such as achievement motivations and academic emotions, suggest the importance of further exploring these constructs. The presented qualitative and quantitative results provide starting points for further research.

\section{Limitations and Future Research}

Despite its strengths, there are limitations that should be kept in mind when interpreting the findings. Firstly, the cross-sectional design of the present study cannot provide information about causal relationships between the examined constructs. Future longitudinal studies could shed light on possible causal relationships, draw conclusions about their directions, and investigate the temporal stability of the attitudes and beliefs of university students and lecturers about educational theories.

Secondly, our analyses and findings are based on a relatively small sample of German students and lecturers from one university. Although, we presume that the interrelations of the examined constructs are generalizable due to similar underlying psychological mechanisms, future research should aim to replicate the findings with larger samples of students and lecturers from universities in different countries, since we cannot rule out that our data might have been biased. Conducting cross-cultural studies may be an especially interesting endeavor to gain information about students' and lecturers' understandings of 
educational theories as there are conceptual differences of educational theories in Germanspeaking vs. English-speaking countries (Biesta, 2013).

Finally, it is important to keep in mind that we used interviews to assess the participants' attitudes and beliefs. Although this approach was particularly appropriate for the explorative purpose of the present research (finding out if and what types of attitudes and beliefs students and lecturers have about educational theories), future studies with larger samples should rely on more economical instruments such as standardized questionnaires.

\section{Educational Implications and Conclusion}

Although further studies are needed to further investigate the role of attitudes and epistemic beliefs about educational theories for students' and lecturers' individual professionalization, the results of the present study allow us to deduce first implications for educational studies and teacher education. Given that there exists no clear definition of 'educational theories' in the (inter-)national educational literature, we suggest a systematic theoretical clarification, as it is a fundamental term of educational science(s). Distinguishing between educational theories in a narrow and in a wider sense could be a fruitful step to achieve this goal (see Defining educational theories).

As both university students and lecturers perceived educational theories to be rather abstract and vague — which may be linked to the lack of a clear definition in literature - these theories should be addressed explicitly in higher education to broaden students' and lecturers' meta-knowledge about (educational) theories, e.g., regarding their benefits and functions. Concerning the fact that (aspiring) educators are often unaware of their theory-related attitudes and beliefs and their potential interrelations with learning motivation and emotions, it is even more important to foster self-reflection on these aspects. Courses in science theory and propaedeutics could provide opportunities for reflection. This might support professional 
development and promote students' research-based learning as well as lecturers' scholarship of teaching and learning and facilitate (future) evidence-based practice (Dewar et al., 2018).

Taken together, our study provides first insights into the novel topic of students' and teachers' attitudes and beliefs about educational theories, and highlights their relevance. Our findings can be used as a stepping stone for understanding and supporting how individuals react to and deal with educational theories in the course of their professionalization. In particular, this line of research can give rise to strategies and interventions for promoting and maintaining adaptive as well as reducing maladaptive theory-related attitudes and beliefs. 


\section{References}

Author 2019 [details removed for peer review]

Aubrey, K., \& Riley, A. (2019). Understanding and using educational theories (2nd ed.). Sage.

Baumert, J., \& Kunter, M. (2013). The coactiv model of teachers' professional competence. In M. Kunter (Ed.), Mathematics teacher education: Vol. 8. Cognitive activation in the mathematics classroom and professional competence of teachers: Results from the COACTIV project (pp. 25-48).

Biesta, G. J. J. (2013). On the idea of educational theory. In B. J. Irby, G. Brown, R. LaraAlecio, \& S. Jackson (Eds.), The handbook of educational theories (pp. 5-16). IAP.

Carr, W. (2006). Education without theory. British Journal of Educational Studies, 54(2), 136-159. https://doi.org/10.1111/j.1467-8527.2006.00344.x

Creswell, J. W., \& Creswell, J. D. (2018). Research design: Qualitative, quantitative, and mixed methods approaches (5th ed.). Sage.

Dewar, J. M., Bennett, C. D., \& Fisher, M. A. (2018). The scholarship of teaching and learning: A guide for scientists, engineers, and mathematicians. Oxford University Press.

Dietrich, J., Viljaranta, J., Moeller, J., \& Kracke, B. (2017). Situational expectancies and task values: Associations with students' effort. Learning and Instruction, 47, 53-64. https://doi.org/10.1016/j.learninstruc.2016.10.009

Dunn, T. J., Baguley, T., \& Brunsden, V. (2014). From alpha to omega: A practical solution to the pervasive problem of internal consistency estimation. British Journal of Psychology, 105(3), 399-412. https://doi.org/10.1111/bjop.12046

Eagly, A. H., \& Chaiken, S. (2007). The advantages of an inclusive definition of attitude. Social Cognition, 25(5), 582-602. https://doi.org/10.1521/soco.2007.25.5.582 
Flick, U. (2018). An introduction to qualitative research (6th ed.). Sage.

AERA [American Educational Research Association] (2011). Code of ethics. https://www.aera.net/Portals/38/docs/About_AERA/CodeOfEthics\%281\%29.pdf

Gitlin, A., Barlow, L., Burbank, M. D., Kauchak, D., \& Stevens, T. (1999). Pre-service teachers' thinking on research: Implications for inquiry oriented teacher education. Teaching and Teacher Education, 15(7), 753-769.

Green, H. J., \& Hood, M. (2013). Significance of epistemological beliefs for teaching and learning psychology: A review. Psychology Learning \& Teaching, 12(2), 168-178. https://doi.org/10.2304/plat.2013.12.2.168

Hofer, B. K., \& Pintrich, P. R. (1997). The development of epistemological theories: Beliefs about knowledge and knowing and their relation to learning. Review of Educational Research, 67(1), 88-140. https://doi.org/10.3102/00346543067001088

Hofer, B. K. (2016). Epistemic cognition as a psychological construct: Advancements and challenges. In J. A. Greene, W. A. Sandoval, \& I. Bråten (Eds.), Handbook of epistemic cognition (pp. 19-38).

Irby, B. J., Brown, G., Lara-Alecio, R., \& Jackson, S. (2013). Preface. In B. J. Irby, G. Brown, R. Lara-Alecio, \& S. Jackson (Eds.), The handbook of educational theories (pp. xvii-xviii).

Kraus, S. J. (1995). Attitudes and the prediction of behavior: A meta-analysis of the empirical literature. Personality and Social Psychology Bulletin, 21(1), 58-75. https://doi.org/10.1177/0146167295211007

Krippendorff, K. (2019). Content analysis: An introduction to its methodology (4th ed.). Sage.

Kuckartz, U. (2014). Qualitative text analysis: A guide to methods, practice \& using software. Sage. 
Lenzen, D. (2004). Pädagogische Grundbegriffe. Band 1 [Basic pedagogical terms. Volume 1]. Rowohlt.

Leś, T. (2017). The research potential of educational theory: On the specific characteristics of the issues of education. Educational Philosophy and Theory, 49(14), 1428-1440. https://doi.org/10.1080/00131857.2017.1313716

Maio, G. R., Haddock, G., \& Verplanken, B. (2019). The psychology of attitudes \& attitude change (3th ed.). Sage.

Marsh, H. W. (1982). SEEQ: A reliable, valid, and useful instrument for collecting students' evaluations of university teaching. British Journal of Educational Psychology, 52(1), $77-95$.

Mason, L., Boscolo, P., Tornatora, M. C., \& Ronconi, L. (2013). Besides knowledge: A cross-sectional study on the relations between epistemic beliefs, achievement goals, self-beliefs, and achievement in science. Instructional Science, 41(1), 49-79. https://doi.org/10.1007/s11251-012-9210-0

Matthes, E. (2007). Was können und was sollen angehende Lehrerinnen und Lehrer in einem wissenschaftlichen Studium der Pädagogik lernen [What can and what should prospective teachers learn in the scientific study of pedagogy]? Bildung und Erziehung, 60(2), 149-163.

Merk, S., Rosman, T., Rueß, J., Syring, M., \& Schneider, J. (2017). Pre-service teachers' perceived value of general pedagogical knowledge for practice: Relations with epistemic beliefs and source beliefs. PloS One, 12(9), e0184971. https://doi.org/10.1371/journal.pone.0184971

Vogel, P. (2019). Grundbegriffe der Erziehungs- und Bildungswissenschaft [Basic concepts of educational science]. Budrich. 
Parr, J. M., \& Timperley, H. S. (2008). Teachers, schools and using evidence: Considerations of preparedness. Assessment in Education: Principles, Policy \& Practice, 15(1), 5771. https://doi.org/10.1080/09695940701876151

Pekrun, R., Goetz, T., Frenzel, A. C., Barchfeld, P., \& Perry, R. P. (2011). Measuring emotions in students' learning and performance: The achievement emotions questionnaire (AEQ). Contemporary Educational Psychology, 36(1), 36-48. https://doi.org/10.1016/j.cedpsych.2010.10.002

R Core Team. (2020). R: A language and environment for statistical computing (Version 1.1.463) [Computer Software]. https://www.R-project.org/

Richardson, V. (1996). The role of attitudes and beliefs in learning to teach. In J. P. Sikula, T. Buttery, \& E. Guyton (Eds.), Handbook of research on teacher education: A project of the association of teacher educators (pp. 102-119).

Rodríguez, L.-F., Ramos, F., \& Wang, Y. (2012). Cognitive computational models of emotions and affective behaviors. International Journal of Software Science and Computational Intelligence, 4(2), 41-63. https://doi.org/10.4018/jssci.2012040103

Schraw, G., \& Olafson, L. (2015). Assessing teachers' beliefs: Challenges and solutions. In H. Fives \& M. G. Gill (Eds.), International handbook of research on teachers' beliefs (pp. 87-105).

Shulman, L. S. (1987). Knowledge and teaching: Foundations of the new reform. Harvard Educational Review, 57(1), 1-23.

Sinatra, G. M. (2016). Thoughts on knowledge about thinking about knowledge. In J. A. Greene, W. A. Sandoval, \& I. Bråten (Eds.), Handbook of epistemic cognition (pp. 479-491). 
Wicker, A. W. (1969). Attitudes versus actions: The relationship of verbal and overt behavioral responses to attitude objects. Journal of Social Issues, 25(4), 41-78. https://doi.org/10.1111/j.1540-4560.1969.tb00619.x

Witzel, A., \& Reiter, H. (2012). The Problem-centred interview: Principles and practice. Sage.

Ziegler, A., Dresel, M., \& Stoeger, H. (2008). Addressees of performance goals. Journal of Educational Psychology, 100(3), 643-654. https://doi.org/10.1037/00220663.100.3.643 


\section{Foodnotes}

${ }^{1}$ All questions of the interview guide are translations of the original German instrument.

${ }^{2}$ To illustrate the findings, we included exemplary quotations from the interviews with the 32 students (S01-32) and the 12 lecturers (L01-12) of educational science and teacher education. The number, that follows the colon indicates the paragraph from which the quote was taken. 


\section{Table 1}

Classification of the Interviewees Regarding Their Theory-Related Attitudes and Beliefs

\begin{tabular}{ccccc}
\hline & \multicolumn{3}{c}{ Attitudes About Educational Theories } \\
\cline { 2 - 5 } $\begin{array}{c}\text { Beliefs About } \\
\text { Educational Theories }\end{array}$ & & Negative & $\begin{array}{c}\text { Neutral/ } \\
\text { Ambivalent }\end{array}$ & Positive \\
\hline \multirow{2}{*}{ Naive } & Students & 5 & 8 & 0 \\
& Lecturers & 0 & 0 & 0 \\
Both & $5(11.4 \%)$ & $8(18.2 \%)$ & $0(0 \%)$ \\
Partly Daifve, & Students & 3 & 5 & 4 \\
Lecturers & 0 & 2 & 3 \\
Differentiated & Both & $3(6.8 \%)$ & $7(15.9 \%)$ & $7(15.9 \%)$ \\
& Students & 3 & 1 & 3 \\
& Lecturers & 0 & 3 & 4 \\
\hline
\end{tabular}

Note. Frequencies of 32 students and 12 lecturers of educational studies and teacher education) are displayed. "Both" shows the frequencies and proportions for the total sample $(N=44)$. 


\section{Table 2}

Correlational Statistics for Students' and Lecturers' Theory-Related Attitudes and Beliefs and Aspects of Learning and Instruction

\begin{tabular}{|c|c|c|c|c|c|c|c|c|c|c|}
\hline & \multirow{2}{*}{ Sample item } & & \multirow{2}{*}{$M$} & \multirow{2}{*}{$S D$} & \multicolumn{2}{|c|}{ Range } & \multirow{2}{*}{ Skew } & \multirow[b]{2}{*}{$\omega_{\mathrm{H}}$} & \multirow{2}{*}{$\begin{array}{l}\text { Attitudes About } \\
\text { Educational } \\
\text { Theories } \\
\end{array}$} & \multirow{2}{*}{$\begin{array}{c}\text { Beliefs About } \\
\text { Educational } \\
\text { Theories }\end{array}$} \\
\hline & & & & & Theoretical & Actual & & & & \\
\hline \multicolumn{11}{|l|}{ Motivation } \\
\hline \multirow{3}{*}{ Subjective Task Value } & \multirow{3}{*}{$\begin{array}{l}\text { It is very useful to know a lot } \\
\text { about educational theories. }\end{array}$} & Students & 4.07 & 1.16 & \multirow{3}{*}{$1-6$} & $1.00-6.00$ & 0.15 & .80 & $.80 * *$ & $.37 *$ \\
\hline & & Lecturers & 4.39 & 1.39 & & $2.44-6.00$ & -0.29 & .86 & $.76^{* *}$ & .05 \\
\hline & & Both & 4.16 & 1.22 & & $1.67-6.00$ & 0.05 & .77 & $.74 * *$ & $.32 *$ \\
\hline \multirow{3}{*}{ Learning Approach Goals } & Regarding educational theories, I want & Students & 6.84 & 1.05 & \multirow{3}{*}{$1-8$} & $5.00-8.00$ & -0.49 & .95 & $.36^{*}$ & $.36^{*}$ \\
\hline & to constantly improve my & Lecturers & 6.79 & 1.29 & & $4.25-8.00$ & -0.79 & .89 & $.68^{*}$ & -.04 \\
\hline & competences. & Both & 6.83 & 1.10 & & $4.25-8.00$ & -0.59 & .91 & $.38^{*}$ & .22 \\
\hline \multirow{3}{*}{ Work Avoidance Goals } & \multirow{3}{*}{$\begin{array}{l}\text { Regarding educational theories, it is } \\
\text { important to me to have little to do. }\end{array}$} & Students & 3.72 & 1.66 & \multirow{3}{*}{$1-8$} & $1.00-7.00$ & 0.04 & .85 & $-.55^{* *}$ & $-.46^{* *}$ \\
\hline & & Lecturers & 2.15 & 1.27 & & $1.00-4.75$ & 1.37 & .94 & -.49 & -.01 \\
\hline & & Both & 3.29 & 1.71 & & $1.00-7.00$ & 0.32 & .89 & $-.65^{* *}$ & $-.50^{* *}$ \\
\hline \multirow{3}{*}{$\begin{array}{l}\text { Interest in Educational } \\
\text { Theories }\end{array}$} & \multirow{3}{*}{$\begin{array}{l}\text { How high is your current level of } \\
\text { interest in educational theories? }\end{array}$} & Students & 3.65 & 1.02 & \multirow{3}{*}{$1-5$} & $2.00-5.00$ & -0.22 & \multirow{3}{*}{-} & $.71 * *$ & $.36^{*}$ \\
\hline & & Lecturers & 3.82 & 1.17 & & $2.00-5.00$ & -0.50 & & $.90 * *$ & .28 \\
\hline & & Both & 3.62 & 1.05 & & $2.00-5.00$ & -0.27 & & $.68 * *$ & .28 \\
\hline \multicolumn{11}{|l|}{ Academic Emotions } \\
\hline \multirow{3}{*}{ Enjoyment } & \multirow{3}{*}{$\begin{array}{l}\text { I enjoy dealing with educational } \\
\text { theories. }\end{array}$} & Students & 3.67 & 1.35 & \multirow{3}{*}{$1-6$} & $1.00-6.00$ & -0.04 & \multirow{3}{*}{-} & $.75 * *$ & $.54 * *$ \\
\hline & & Lecturers & 4.00 & 1.40 & & $1.50-6.00$ & -0.50 & & $.70^{*}$ & .20 \\
\hline & & Both & 3.76 & 1.35 & & $1.00-6.00$ & -0.14 & & $.71^{* *}$ & $.45^{* *}$ \\
\hline \multirow{3}{*}{ Boredom } & \multirow{3}{*}{$\begin{array}{l}\text { Dealing with educational theories } \\
\text { bores me. }\end{array}$} & Students & 2.38 & 1.10 & \multirow{3}{*}{$1-6$} & $1.00-5.00$ & 0.67 & \multirow{3}{*}{-} & $-.71 * *$ & -.21 \\
\hline & & Lecturers & 1.75 & 1.27 & & $1.00-5.00$ & 1.80 & & -.53 & .04 \\
\hline & & Both & 2.20 & 1.17 & & $1.00-5.00$ & 0.68 & & $-.67 * *$ & -.21 \\
\hline \multirow{3}{*}{ Anxiety } & & Students & 2.42 & 1.13 & & $1.00-6.00$ & 0.44 & - & .14 & -.03 \\
\hline & theories J'm often tense and nervous & Lecturers & 1.50 & 0.93 & $1-6$ & $1.00-4.00$ & 2.14 & - & -.57 & .48 \\
\hline & & Both & 2.17 & 1.15 & & $1.00-6.00$ & 0.82 & & -.20 & -.13 \\
\hline
\end{tabular}




\section{Table 2 (continued)}

Correlational Statistics for Students' and Lecturers' Theory-Related Attitudes and Beliefs and Aspects of Learning and Instruction

\begin{tabular}{|c|c|c|c|c|c|c|c|c|c|c|}
\hline & \multirow[b]{2}{*}{ Sample item } & & \multirow[b]{2}{*}{$M$} & \multirow{2}{*}{$S D$} & \multicolumn{2}{|c|}{ Range } & \multirow{2}{*}{ Skew } & \multirow[b]{2}{*}{$\omega_{\mathrm{H}}$} & \multirow{2}{*}{$\begin{array}{c}\text { Attitudes About } \\
\text { Educational } \\
\text { Theories } \\
\end{array}$} & \multirow{2}{*}{$\begin{array}{c}\text { Beliefs Abou } \\
\text { Educational } \\
\text { Theories }\end{array}$} \\
\hline & & & & & Theoretical & Actual & & & & \\
\hline \multicolumn{11}{|c|}{ Sociodemographic Variables } \\
\hline \multirow{3}{*}{ Gender } & \multirow{3}{*}{ Gender: male or female } & Students & 0.56 & 0.50 & \multirow{3}{*}{$0-1$} & $0-1$ & -0.27 & & -.24 & -.08 \\
\hline & & Lecturers & 0.50 & 0.52 & & $0-1$ & 0.00 & - & -.17 & -.17 \\
\hline & & Both & 0.55 & 0.50 & & $0-1$ & -0.19 & & -.22 & -.09 \\
\hline \multirow{3}{*}{ Age } & \multirow{3}{*}{ Age: ___ (in years) } & Students & 23.90 & 3.03 & \multirow{3}{*}{$>0$} & $18-32$ & 0.54 & \multirow{3}{*}{-} & .34 & -.15 \\
\hline & & Lecturers & 42.64 & 10.4 & & $32-64$ & 0.96 & & -.02 & .60 \\
\hline & & Both & 28.81 & 10.1 & & $18-64$ & 1.86 & & $.40 * *$ & $.43^{* *}$ \\
\hline Semester & $\begin{array}{r}\text { I am currently in my } \\
\text { semester. }\end{array}$ & Students & 3.87 & 2.68 & $1-15$ & $1-11$ & 0.94 & - & -.26 & -.15 \\
\hline $\begin{array}{l}\text { Teaching } \\
\text { Experience }\end{array}$ & $\begin{array}{c}\text { How many years of } \\
\text { professional experience as a } \\
\text { university lecturer do you have? }\end{array}$ & Lecturers & 13.40 & 10.1 & $1-45$ & $1-34$ & 0.87 & & -.09 & .49 \\
\hline
\end{tabular}

Note. $N=44$ (32 students and 12 lecturers of educational studies and teacher education; the last row shows the frequencies and proportions for the total sample $(N=44)$; Internal consistencies (expressed through $\omega_{\mathrm{H}}$ ) were only calculated for scales with more than four items;

Bivariate correlations: Pearson's $r$ for continuous variables and Spearman's $\rho$ for ordinal variables; * $p<.05 . * *: p<.01$. 